\title{
Turismo e cultura no Brasil: questões incompativeis?
}

\author{
Maria Luiza M. Mendonça*
}

\section{Resumo}

A autora aborda a necessidade de se modificar a maneira como se relacionam, hoje, turismo c cultura. A compreensão dessa relação é fundamental para se viabilizar um desenvolvimento turístico que não destrua o meio ambiente c nem desrespeite as populações locais. Um desenvolvimento baseado numa visão não mercantil do patrimônio histórico, cultural e artístico.

Palavras-chave: turismo; cultura; patrimônio histórico-cultural.

Para compreender a importância que o turismo vem adquirindo atualmente como um dos segmentos que mais crescem na economia mundial e a relação que esse fluxo errático de indivíduos estabelece com as culturas locais, é preciso relacionar a sua expansão ao processo mais amplo da globalização. Este processo, entendido como a atual etapa ampliada de desenvolvimento do capitalismo, refere-se não apenas à produção, circulação e consumo de mercadorias, capitais, informações e comunicações, bem como à maior facilidade de acesso de camadas cada vez mais amplas da população aos mais variados tipos de informação. O aprimoramento dos meios de transporte e o incentivo dado pelos media para que se consumam também lugares, culturas e experiências possibilitam e favorecem o deslocamento cada vez mais freqüente de indivíduos.

Esse incremento na circulação de informações e de indivíduos atua tanto no sentido de facilitar a internacionalização de capitais e de mercadorias como também na esfera das culturas, idéias,

* Relações Públicas, mestre em Comunicação e Marketing, doutoranda pela ECA/USP, professora da Faculdade de Comunicação e Biblioteconomia da Universidade Federal de Goiás e pesquisadora do CELACC.

Comun. inf., v.1, n. 1, p. 95-113, jan.jun. 1998 
comportamentos, éticas e estéticas, tornando-a mais suscetíveis a influências várias e mutáveis. Esse dinamismo que se verifica também no intercâmbio de idéias e de padrões culturais, viabilizado em grande parte pela atuação dos media e pelo contínuo e intenso deslocamento de indivíduos, propicia a disseminação de estilos de vida, valores e formas de atribuir significados sem que se saiba exatamente de onde provêm: a virtual diluição das fronteiras geográficas e nacionais torna possível o surgimento de processos de desterritorialização das referências sobre as quais se constroem as identidades individuais e coletivas. Nesse sentido, o vigoroso curso das comunicações pode ainda afetar, redirecionando, as formas de perceber o mundo, de atribuir sentido e de construir uma sociabilidade, ao redefinir padrões e modelos de comportamento e de expressar identidades em que o "ter" prevalece sobre o "ser", e em que o consumo e a ostentação de produtos materiais e simbólicos adquirem um papel diferenciador e identificador.

Dentro desse contexto o turismo pode ser encarado como uma atividade que ultrapassa uma simples forma de utilização do tempo livre, do ócio, e que se aproxima cada vez mais de um novo tipo de consumo. E melhor, pode ser visto como parte da cultura de consumo e do consumo cultural. Na cultura de consumo o ato de consumir excede em muito uma certa racionalidade econômica e passa a ser motivado por "razões" mais ligadas à comunicação de uma intenção, de um reconhecimento ou de uma identificação socialmente visivel em que a posse ou fruição de determinado bem insere o indivíduo no mundo de uma forma determinada. Da mesma forma, em relação ao consumo de produtos culturais, a lógica e os princípios do mercado são estendidos aos bens culturais e simbólicos e as preferências por certos produtos ou estilos, sejam elas individuais ou de determinados grupos ou estratos sociais, revelam também a intenção de comunicar, distinguir e identificar. Em uma perspectiva que contempla a existência de um valor simbólico agregado aos bens materiais e culturais, Garcia Canclini relaciona o consumo cultural aos processos de elaboração de identidades culturais de grupos, classes e frações de classes graças ao poder de diferenciação e distinção simbólica que socialmente se confere aos produtos e aos indivíduos pelo que consomem e pela forma como

Comun. inf., v.1, n. 1, p. 95-113, jan./jun. 1998 
consomem. Desse ponto de vista, as mercadorias e mesmo os produtos culturais passam a ser úteis também, e muitas vezes principalmente, para comunicar diferenças e distinções sociais. $^{1}$

Pensar o desenvolvimento do turismo implica, por um lado, inseri-lo em um processo global em que prevalece a ampla circulação de capitais e mercadorias, indivíduos, idéias e prociu tos culturais e simbólicos, e dentro do qual ganham relevo os apelos mercadológicos para a experimentação também de novos lugares, sensações e diferenças culturais. Por outro lado, não se pode deixar de considerá-lo como um fator de fomento à ampla circulação de idéias e de cultura que dá impulso a transformações nas culturas locais e em suas formas de expressão.

Em temos empíricos, a interferência do turismo na produção cultural pode ser observada, dentre outros ângulos, a partir da "folclorização" de manifestações culturais das classes populares, tais como danças e lutas - capoeira e maculelê, por exemplo "embelezados" para apresentações públicas, como também pelo ângulo espacial, a partir da importância que vem adquirindo o redirecionamento de espaços urbanos especificamente destinados à produção e ao consumo de produtos culturais e simbóli$\cos$. Esta questão espacial se manifesta concretamente nos programas de revitalização e recuperação de áreas deterioradas de centros urbanos no sentido de desenvolver centros destinados à produção artística e cultural e promover a sua recuperação à custa da expulsão dos antigos moradores, geralmente de baixa renda. Um exemplo dessa prática, que é mundial, pode ser observado através de reportagens publicadas na imprensa sobre a restauração de centros antigos e festejada pelos media como novos atrativos turísticos. ${ }^{2}$

Não se pretende, a partir das idéias expostas aqui, condenar iniciativas que visem à expansão do turismo no Brasil, ao contrário, pretende-se apontar meios para que essa expansão seja viabilizada de forma a promover a integração harmônica entre a recepção de turistas e o respeito ao patrimônio cultural e natural e às populações locais. Com esses objetivos em mente, pretende-se identificar o papel que tanto o poder público - através de algumas intervenções do Ministério da Indústria, do Co- 
mércio e do Turismo e da Embratur no setor - como os media desempenham no sentido de promover um tipo de turismo que não seja predatório e que seja capaz de gerar recursos e empregos e de realizar o seu potencial "efeito multiplicador". 3

\section{Turismo: incentivos e ações oficiais}

O turismo é um dos segmentos da economia mundial que mais crescem atualmente. Dados consolidados e publicados pela Organização Mundial do Turismo ${ }^{4}$ apontam o faturamento mundial com turismo em 3,4 trilhões de dólares, o que corresponde a $10 \%$ do PIB mundial, oferece 205 milhões de empregos diretos e gera 350 bilhões de dólares em impostos diretos. Os gastos com atividades turísticas correspondem a $13 \%$ dos gastos totais dos consumidores, inferiores apenas às despesas com alimentação. Na mesma publicação prevê-se, ainda, uma taxa média de crescimento mundial para o decênio 1990-2000 em torno de 3,2\% ao ano, apontando-o como uma das atividades econômicas com maior potencial de crescimento atualmente.

$\mathrm{O}$ expansão da atividade turística em âmbito mundial vem indicando ao poder público a necessidade de que o país se torne capaz de atrair e acolher um número crescente de turistas, especialmente aqueles vindos do exterior, pois se os números da Organização Mundial de Turismo apontam para um incremento nessa atividade, no Brasil o ingresso de turistas estrangeiros vem caindo. Dados fornecidos pela Polícia Federal à imprensa brasileira demonstram que a entrada de turistas estrangeiros no País em 1995 superou, pela primeira vez desde 1986, o número de 2 milhões de visitantes. ${ }^{5}$ Este fato vem sendo atribuído à falta de incentivo do governo ao setor, à ausência de uma política e de um planejamento de longo prazo para o desenvolvimento desta atividade, à falta de publicidade e de campanhas de marketing, que atraia estrangeiros sem apelar para as possibilidades de turismo sexual, e aos problemas estruturais, como a miséria crônica, a violência urbana e a falta de infra-estrutura, que causam transtornos aos moradores e visitantes em épocas de "alta temporada". Em artigo assinado para o jornal $O$ Esta-

Comun. inf., v.1, n. 1, p. 95-113, jan./jun. 1998 
Io de S. Paulo, o ex-presidente da Associação Brasileira das Indústrias de Hotéis afirma que

\begin{abstract}
a ampliação da malha turística em algumas regiões não é acompanhada pela necessária preparação de quadros; a efervescência dos fluxos turísticos, que ocorre geralmente nos momentos de pico das altas estações, provoca tumulto nos aeroportos e freqüentes situações de overbooking nos hotéis; o planejameni dos espaços turísticos, com suas construções, resvala em linguagens arquitetônicas disformes, algumas chegando a agredir as próprias condições naturais(...) (com a conseqüente) ocupação desorganizada dos espaços, a agressão a santuários ecológicos e o desmonte de belos territórios naturais ${ }^{6}$.
\end{abstract}

Essas e outras inquietações trazidas pelo crescimento do turismo no Brasil estão estampadas nas críticas feitas ao poder público, especificamente no que se refere à ausência de uma política adequada de incentivo ao turismo. A falta de um planejamento para o setor acentua o caráter predatório de atividades de massa não contempladas com planos e programas integrados de desenvolvimento que possibilitem a integração harmônica entre os turistas, as populações locais e seus recursos culturais e naturais. Essa preocupação com a ausência de planejamento atinge até mesmo os proprietários de hotéis que se beneficiam exatamente de recursos naturais ameaçados pelo turismo predatório. Em Porto de Galinhas, litoral de Pernambuco, foi criada uma associação (Associação dos Hotéis de Porto de Galinhas) com o objetivo de tentar impedir que o crescimento rápido e sem estrutura adequada transforme Porto de Galinhas em uma nova Porto Seguro - local onde a explosão do número de turistas na alta temporada já provocou falta de água, bebidas e "congestionamento" até mesmo no aeroporto.

O poder público, obviamente, sensibilizou-se com a questão do desenvolvimento da atividade do turismo no Brasil, mais pelos números de turistas estrangeiros e de divisas que deixaram de entrar e circular no País do que com as críticas de empresários do setor.

$\mathrm{O}$ presidente da Embratur, Caio Luís de Carvalho, divulgou à imprensa ${ }^{7}$ o documento "Política Nacional de Turismo", prepara-

Comun. inf., v.1, n. 1, p. 95-113, jan./jun. 1998 
do pela Câmara Setorial do Turismo, que trata das diretrizes e estratégias para o turismo no Brasil, visando aumentar para 3,8 milhões o ingresso de turistas estrangeiros no país. A nova política de turismo aponta quatro objetivos:

1 - "melhorar a infra-estrutura básica nas regiões turísticas;

2 - aperfeiçoar a qualidade dos serviços oferecidos (treinamento de mão de obra);

3 - alterar a legislação que afeta o turismo para melhorar o tratamento dado aos visitantes; e

4 - aumentar os recursos em marketing e promoções de turismo".

Pouco tempo depois, na abertura do $38^{\circ}$ Congresso Nacional de Hotéis, realizado no Rio de Janeiro em 1996, a então Ministra da Indústria, Comércio e Turismo, Dorothéa Werneck, anunciou investimentos da ordem de 3,5 bilhões de dólares para a expansão e reforma de grandes redes de hotéis e cerca de 1 bilhão de dólares para investimentos em "parques temáticos", além da isenção de IPI e de Imposto de Importação na compra de equipamentos para esses parques ${ }^{8}$.

Ainda em 1996, o Ministério da Indústria, Comércio e Turismo e a Embratur lançaram, em conjunto, mais três pacotes de programas: o de municipalização do turismo, e de diretrizes para o ecoturismo e do novo sistema de reclassificação de hotéis.

O Programa de Municipalização do Turismo é descrito como

um processo de conscientização da população que será diretamente beneficiada pelas ações que serão desenvolvidas no próprio municipio (...) Trata-se de um programa voltado à conscientização dos municípios (?) sobre o fato de que somente possuir atrativos ou potencial turístico não é suficiente para que a atividade cresça. O turismo só poderá produzir benefícios sociais, econômicos e ambientais se for planejado c gerenciado dentro de um contexto regional, nacional e até internacional.

Seus principais objetivos são:

a) conscientizar a sociedade para a importância do turismo como instrumento de crescimento econômico, geração de empregos, melhoria da qualidade de vida da população e preservação de seu patrimônio natural e cultural;

Comun. inf., v.1, n. 1, p. 95-113, jan./jun. 1998 
b) dotar os municípios brasileiros com potencial turístico de condições técnicas e organizacionais para promover o desenvolvimento da atividade turística;

c) descentralizar as ações de planejamento, motivando o município como um todo, transmitindo as técnicas básicas do planejamento turístico de forma a capacitá-los a elaborar seus próprios planos de desenvolvimento;

d) promover o fortalecimento das relações entre os órgãos públicos federal, estadual e municipal, com a iniciativa privada dos municípios envolvidos;

e) acelerar a expansão e a melhoria da infra-estrutura turística, buscando parcerias para investimento na região;

f) incentivar o intercâmbio com entidades nacionais e internacionais a fim de promover captação e geração de eventos para os municipios no sentido de minimizar o efeito da sazonalidade;

g) contribuir para a formação e a capacitação dos profissionais que prestam serviços para o turismo, visando à qualidade e produtividade;

h) difundir os modelos de Conselhos, Fundos e outros instrumentos de municipalização.

As "Diretrizes para a Politica Nacional de Ecoturismo" loram elaboradas com a participação do Ministério do Meio Ambiente. Este documento define o ecoturismo como

um segmento da atividade turística que utiliza, de forma sustentável, o patrimônio natural e cultural, incentiva sua conservação e busca a formação de uma consciência ambientalista através da interpretação do ambiente, promovendo o bem-estar às populações envolvidas.

Os objetivos das Diretrizes são os seguintes:

a) Compatibilizar as atividades de ecoturismo com a conservação de áreas naturais;

b) fortalecer a cooperação interinstitucional;

c) possibilitar participação efetiva de todos os segmentos atuantes no setor;

d) promover e estimular a capacitação de recursos humanos para o ecoturismo;

e) promover, incentivar e estimular a criação e a melhoria da infra-estrutura para a atividade do ecoturismo;

f) promover o aproveitamento do ecoturismo como veículo de educação ambiental.

Comun. inf., v.1, n. 1, p. 95-113, jan.jun. 1998 
As ações estratégicas necessárias para alcançar esses objetivos propostos são também especificadas no documento:
a) regulamentação do ecoturismo;
b) fortalecimento e interação institucional;
c) formação e capacitação dos recursos humanos;
d) controle de qualidade do produto ecoturístico;
e) gerenciamento de informações;
f) incentivos ao desenvolvimento do ecoturismo;
g) implantação e adequação de infra-estrutura;
h) conscientização e informação ao turista;
i) participação comunitária.

Quanto ao sistema de classificação de hotéis, a Embratur propõe um sistema de reavaliação que substitui as antigas "estrelas" conferidas aos estabelecimentos por um selo de qualidade, de caráter opcional, que leva em consideração, além da avaliação das instalações fisicas, a área ambiental e a qualidade dos serviços oferecidos. ${ }^{9}$

Está bastante claro que a preocupação do poder público com as questões relativas ao desenvolvimento das atividades turísticas se restringe mais ao discurso e às propostas, pois mesmo as ações "estratégicas" podem ser consideradas muito mais como intenções, dado o seu caráter vago, do que um definição clara sobre o que deve ser feito, quem deve fazer, em quanto tempo e com que resultados. Ao relacionar os dois documentos, o "Programa Nacional de Municipalização do Turismo" e as "Diretrizes para a Política Nacional de Ecoturismo", vê-se que o Estado (governo federal) transfere muito de suas atribuições anteriores para os municípios - quase todos pobres e endividados - com sugestões para que se criem "parcerias" com a iniciativa privada uma maneira de delegar à esfera privada atribuições próprias da esfera pública. Os objetivos da iniciativa privada são relacionados à obtenção de lucros e a sua forma de medir eficiência e eficácia pode não ser - e freqüentemente não é - a mesma ou a mais adequada para a preservação de recursos naturais e também de expressões culturais. É da própria natureza da iniciativa privada converter aquilo que toca em mercadoria e, no Brasil, as informações de que se dispõe sobre a atuação de empresas privadas em assuntos ligados ao meio ambiente não 
is recomendam como parcerias ideais em projetos preservacionistas.

Por outro lado, quando se refere a investimentos, privilegiam-se as grandes redes e os grandes empreendimentos que como os parques temáticos - aliam turismo e diversão e requeem grande concentração de capital. Os pequenos proprietárius, assim como programas destinados à valorização, sem mercantilização, de expressões culturais populares enquanto potencial de atração turística inexistem nos documentos elaborados pelo poder público. Apesar dessa exclusão, são exatamente as manifestações culturais populares, ao lado dos recursos naturais, os grandes atrativos turísticos. São as danças, as restas, os ritmos, os artesanatos e até a maneira de ser de algumas populações os elementos valorizados como atraentes.

Paradoxalmente, as iniciativas governamentais destinam-se a cativar o turista estrangeiro, enquanto um estudo da própria Embratur citado em reportagem da revista Veja ${ }^{10}$ estimava que no ano de 1996 aproximadamente 12 milhões de brasileiros deveriam fazer pelo menos uma viagem a passeio, e que esta viagem poderia ser realizada internamente. Para o órgãos oficiais de incentivo do turismo esta é uma realidade aparentemente pouco conhecida e desvalorizada, pois pensa-se sempre no visitante estrangeiro, mas é uma realidade em que os media e as agências de turismo vêm investindo há algum tempo.

\section{A força dos media}

O turismo está presente nos media brasileiros de forma bastante consolidada, haja vista a existência de cadernos dedicados ao assunto nos principais jornais do país, sem falar na força da televisão que, ao mostrar em seus programas - novelas, principalmente - cenas locadas em determinadas cidades, consegue provocar uma efervescência turística na região ( $O$ então presidente da Fundação para o Desenvolvimento do Turismo de Fortaleza, Edgar Sá, afirmou ao jornal O Estado de S. Paulo ${ }^{11}$ que "o sonho de qualquer estado do Nordeste é ser usado como locação para uma novela da Globo"). Apesar da importância da televisão como veículo de alcance abrangente, neste traba- 


\section{4}

lho são utilizados como fonte os dados coletados por pesquisadores do CELACC ${ }^{12}$ apenas em cadernos especiais de turismo de alguns veículos impressos. A pretensão aqui é mostrar a forma como esses veículos abordam assuntos relacionados ao turismo, especificamente no que diz respeito aos roteiros mais anunciados e aos atrativos mais destacados nas reportagens e nas inserções publicitárias feitas pelas agências de viagens. Os dados considerados limitam-se aos relativos ao chamado turismo interno, ou seja, aquele realizado dentro do próprio País. À medida em que se fizer necessário para o esclarecimento da interpretação, pretende-se recorrer a entrevistas com proprietários e gerentes de agências de turismo na cidade de São Paulo e em cidades vizinhas realizadas pelos mesmos pesquisadores.

Foram pesquisados os cadernos de turismo de três jornais de circulação nacional: Jornal do Brasil, $O$ Estado de S. Paulo e Folha de $S$. Paulo, no período compreendido entre julho e dezembro de 1996. Além disso foram realizadas entrevistas com proprietários ou gerentes de agências de turismo procurando avaliar, entre outras questões, aquelas relacionadas com o turismo dentro do Brasil. Neste texto a abordagem centra-se mais nos aspectos relacionados à forma como os elementos culturais são valorizados ou não pelos respectivos veículos e pelos entrevistados, e se existem ou não propostas, fora do âmbito governamental, para que a atividade turística possa se desenvolver no país em beneficio dos turistas, das culturas e das populações locais.

Os dados coletados, no que diz respeito ao turismo interno, dividem-se em duas categorias principais: anúncios e reportagens; e, dentro de cada categoria, a posição ocupada pelo Brasil em relação aos principais roteiros com destino ao exterior: Estados Unidos e Europa. ${ }^{13}$

Do total de anúncios publicados nos jornais, os principais destinos são:

Destinos Anúncios (\%)

$\begin{array}{ll}\text { Estados Unidos } & 17,4 \\ \text { Brasil } & 16 \\ \text { Europa } & 13,3\end{array}$

Comun. inf., v.1, n. 1, p. 95-113, jan./jun. 1998 
Esses roteiros ocupam quase metade $(46,7 \%)$ de todo espaço anunciado; dentre os outros destinos propostos o que mais se destaca é a região do Caribe, com 5,5\% do total de anúncios.

As reportagens foram classificadas de acordo com os locais que privilegiam, com o tipo de turismo abordado, tamanho das matérias, a localização das matérias em páginas pares ou ímpares e a existência de fotos. Estes três últimos itens fornecem a indicação da importância que se pretendeu dar à reportagem.

Do total de reportagens publicadas, extraíram-se os seguintes dados:

\begin{tabular}{lc}
\hline Local & Reportagens (\%) \\
\hline Brasil & 27,8 \\
Europa & 22,3 \\
Estados Unidos & 17,2 \\
\hline
\end{tabular}

Ao cruzar as informações sobre locais abordados pelas reportagens e os seus respectivos tamanhos o quadro alterou-se, e o Brasil aparece com maior freqüência nas pequenas matérias, como pode ser observado na tabela a seguir:

\begin{tabular}{lccc}
\hline $\begin{array}{l}\text { Locais/ } \\
\text { tamanho }\end{array}$ & $\begin{array}{c}\text { pequeno } \\
(\%)\end{array}$ & $\begin{array}{c}\text { médio } \\
(\%)\end{array}$ & $\begin{array}{c}\text { grande } \\
(\%)\end{array}$ \\
\hline Brasil & 43,9 & 32,8 & 26,4 \\
Estados Unidos & 12,5 & 22,6 & 22,4 \\
Europa & 14,4 & 11,3 & 14,6 \\
\hline
\end{tabular}

$\mathrm{O}$ quadro sobre a existência de fotos ilustrando as reportagens também é indicativo do destaque que se quis dar a elas:

\begin{tabular}{lcc}
\hline $\begin{array}{l}\text { Tipo de fotos } \\
\text { locais }\end{array}$ & $\begin{array}{c}\text { coloridas } \\
(\%)\end{array}$ & $\begin{array}{c}\text { preto e branco } \\
(\%)\end{array}$ \\
\hline Brasil & 29,9 & 19,5 \\
Estados Unidos & 13 & 20 \\
Europa & 14,1 & 17,6 \\
\hline
\end{tabular}

Comun. inf., v.1, n. 1, p. 95-113, jan./jun. 1998 
Os locais privilegiados pelas reportagens, ou seja, as localizações em páginas ímpares, podem ser avaliados através dos seguintes percentuais:

\begin{tabular}{lc}
\hline Local & Páginas ímpares (\%) \\
\hline Brasil & 15,3 \\
Estados Unidos & 17,9 \\
Europa & 15,2 \\
\hline
\end{tabular}

A observação desses dados indica que, ao lado dos destinos sugeridos nos anúncios - numericamente muito baixos ao se considerar que o país é bastante extenso e oferece uma variedade de recursos naturais e culturais -, a presença de matérias que tratam de roteiros ou atrativos turísticos locais é pouco representativa de um verdadeiro interesse em ressaltar ou dar a conhecer as potencialidades do país. Deve-se lembrar que os dados aqui interpretados se referem ao Brasil em comparação com os Estados Unidos e Europa, os dois destinos e localidades mais presentes em termos de anúncios e de reportagens, e que o restante do percentual não especificado trata sempre de outros países. Isso quer dizer que do total de destinos sugeridos, no mundo todo, apenas $16 \%$ apontam o Brasil como possibilidade. $\mathrm{O}$ mesmo pode ser dito em relação às reportagens. $\mathrm{E}$ dentro do Brasil, a maior parte das matérias e anúncios se refere à região Sudeste em primeiro lugar - praias e algum patrimônio histórico para ser objeto de visita - seguida pela região Nordeste, onde o principal atrativo turístico são as praias e a possibilidade de fugir da tensão das cidades grandes. A região Nordeste é apresentada em associação à calma, sossego, belas praias e comida boa e barata. É possível que, pelo fato de os dados terem sido coletados entre os meses de julho e dezembro de 1996, a região Nordeste esteja com menor visibilidade do que se a coleta fosse realizada ao longo de todo um ano, de forma a se poder ponderar os dados no que diz respeito à sazonalidade, ou seja à alta ou baixa estação, apesar de que em dezembro já se começa a anunciar viagens para essa região. 
As reportagens também foram classificadas de acordo com o tipo de atrativo turístico que destacavam, se referente ao patrimônio histórico, ou cultural, natural (quando se refere às belezas naturais como principal atrativo), esportivo (inclui pesca), ou mesmo compras, religião. No quadro a seguir podem ser avaliados os principais tipos de turismo abordados nas reportagens. Os menos citados não foram incluídos.

\begin{tabular}{lcccc}
\hline Locais/Tipo & $\begin{array}{c}\text { Cultural } \\
(\%)\end{array}$ & $\begin{array}{c}\text { Natural } \\
(\%)\end{array}$ & $\begin{array}{c}\text { Compras } \\
(\%)\end{array}$ & $\begin{array}{c}\text { Patrimônio } \\
\text { Histórico }\end{array}$ \\
\hline Brasil & 25,64 & 44,8 & 3,2 & 2,7 \\
Estados Unidos & 49,7 & 11 & 10,4 & - \\
Europa & 73,4 & 3,1 & - & 17,2 \\
\hline
\end{tabular}

A observação destes dados informa que muito pouco da cultura brasileira é proposto como fator de interesse turístico tanto pelos anunciantes como pela forma que os jornais tratam as informações, dando destaque aos recursos naturais, especialmente as praias.

A explicação para o fato de os roteiros dentro do Brasil serem menos sugeridos do que aqueles para o exterior e, em se tratando de Brasil, a ênfase recair sobre os recursos naturais, praias sobretudo, pode ser atribuída a, pelo menos duas razões: em primeiro lugar, as agências anunciam o que há de mais caro, porque são exatamente os roteiros mais extensos, distantes e que demandam maior disponibilidade de recursos financeiros. Este fato está explícito nas entrevistas realizadas com os proprietários ou gerentes de agências de viagens. Quando perguntados quais os roteiros mais lucrativos, aqueles poucos que responderam essa questão afirmaram ser os mais caros, ou seja, aqueles para o exterior, principalmente Estados Unidos e Europa. Isso indica que os veículos impressos atendem os desejos de seus anunciantes ao publicar reportagens em que outros países figuram como possíveis roteiros com uma freqüência muito maior do que o Brasil, e a relação entre a publicação de reportagens e a escolha de destinos pelos turistas é inegável. Uma proprietá-

Comun. inf., v.1, n. 1, p. 95-113, jan./jun. 1998 


\section{8}

ria de agência em Santos afirmou: "A mídia divulga os roteiros e a procura aumenta". ${ }^{14}$ Além disso, a imagem que as agências têm do turista brasileiro é estereotipada. Muitos dos gerentes de agências entrevistados afirmaram que o brasileiro procura sobretudo as praias, tem pouco interesse em patrimônio histórico ou em expressões culturais locais, coincidindo quase por completo com os roteiros sugeridos pelas matérias nos jornais pesquisados. Não se quer aqui afirmar que os media determinam que tipo de turismo será priorizado, mas com certeza se pode afirmar que reforçam a tendência para certos tipos de turismo, em especial aquele ligado ao consumo, e o turismo de massa em direção a locais associados a experiências de vida mais intensas. E sua política não contempla a valorização e o (re)conhecimento de manifestações culturais regionais.

Em segundo lugar, existe um desconhecimento e um preconceito em relação à cultura do país e dos brasileiros. Dois depoimentos dados aos pesquisadores do Celacc por gerentes de agências de turismo são exemplos bastante claros deste desconhecimento e deste preconceito:

- É, nosso povo não gosta de cultura... eu estou generalizando, mas não gosta, prefere as praias, curtir...

- Não acredito (em investimentos para a preservação do patrimônio histórico e cultural), porque nós não temos cultura para isso. A nossa cultura é pequena perante a cultura deles (europeus). Na Europa tudo é cultura. O que nós temos para oferecer de cultura? A origem nossa é Porto Seguro, onde houve o descobrimento do Brasil....e depois é mais a beleza natural, as praias são lindas. Rio de Janeiro é uma maravilha. Mas realmente, uma cultura que se tem na Europa... Nós somos novinhos, quinhentos anos.

Claro está que, à parte os interesses puramente comerciais, vigora um absoluto desconhecimento do que é cultura e do que são as formas de expressão cultural, além de um despreparo em termos de conhecimento cultural, uma visão enviesada do que vem a ser cultura. Uma maneira de conceber a cultura que a coloca como uma coleção, um acúmulo de coisas que se possui, e não como algo que se faz, se pratica e se vivencia no cotidia- 
no e que dá sentido ao mundo e à vida. Não seriam, por acaso, a lambada e a lambaeróbica, tão populares em Porto Seguro e que atraem turistas de todos os estados, a hibridação de ritmos e danças genuinamente baianos com influências estrangeiras assimiladas através dos media? E não é exatamente essa forma híbrida de cultura que está vendendo milhões de discos em todo o país?

Além disso, pode-se perceber que vigora uma certa "colonização" intelectual. A este respeito, Cisneros, escrevendo sobre a questão da identidade dos povos latino-americanos em face da submissão aos padrões culturais hegemônicos, afirma com propriedade que

\begin{abstract}
os subgrupos e indivíduos do terceiro mundo que estabelecem contato com a metrópole, incluindo os cientistas, geralmente absorvem junto com a informação útil toda uma forma de ver 0 mundo, e mais cedo ou mais tarde transformam suas estruturas mentais em favor do país dominante. Essa mudança os leva a adotar uma atitude de supcrioridade sobre seus congêneres e a distanciar-se delcs, considerando-os ignorantes, atrasados ou primitivos. Em seguida podem ocorrer duas tendências: ou se começa a planejar a emigração em direção ao centro metropolitano(...) procurando incorporar-se nessa nova cultura, ou se pretende 'salvar' scus conterrâneos do atraso, promovendo acriticamente as práticas culturais hegemônicas obtidas através de seus contatos, para alçá-los ao progresso ou à modernização. No primeiro caso os individuos sonham, desejam pertencer à cultura da metrópole e definem seu projeto de vida em função disso. No segundo caso(...) se busca gerar uma espécie de 'sucursal' da metrópole no próprio território, 'ser como eles ${ }^{15}$
\end{abstract}

Faz parte também desta mentalidade colonizada, ou subalterna, desdenhar e desconhecer o que lhe é próprio, particular e muito diferente das práticas culturais hegemônicas. A interpretação do que está publicado nos jornais, do que revelaram os entrevistados e dos programas governamentais para o turismo examinados aqui deixa claro que as expressões culturais ocupam um lugar de pouco ou nenhum destaque. E o mais grave: estas expressões nem mesmo são reconhecidas como existentes, vivas, dinâmicas, múltiplas e possuidoras de grande variedade e riqueza de formas e conteúdos.

('omun. inf., v.l, n. 1, p. 95-113, jan./jun. 1998 


\section{Turismo e cultura: possibilidades}

As constatações precedentes apontam em direção a uma necessidade de modificar a maneira como se relacionam, hoje, turismo e cultura, principalmente no que diz respeito à forma como estes temas são abordados e divulgados pelos media. É preciso que a visão atual seja alterada no sentido de permitir uma nova forma de conceber cultura e cultura brasileira. É evidente que qualquer tentativa de mudança neste sentido deve passar, obrigatoriamente, pelas escolas: é imperativo que os estudantes tenham contato com os conceitos de cultura, que conheçam as suas formas de expressão e que se familiarizem com as manifestações culturais existentes no Brasil.

Entretanto, existem caminhos que podem, em um prazo mais curto, ser trilhados em busca de um maior reconhecimento das culturas regionais e das possibilidades que estas oferecem de se constituir como fatores de atração turística, sem que percam suas características principais e sem que a inevitável incorporação de elementos provenientes de outras matrizes culturais seja realizada em prejuizo próprio. Para que isto possa ocorrer é necessário que se somem esforços dos diferentes segmentos da sociedade que se interessam por um desenvolvimento turístico capaz de dignificar regiões, culturas e indivíduos. E, para começar, é preciso identificar o que se pretende oferecer como potencial turístico para que se possa, responsavelmente, propor ações. Para tanto, algumas atividades iniciais se impõem:

- Realizar um mapeamento das manifestações culturais festas, artesanatos, danças, recursos naturais - que podem se converter em atrações turísticas, identificando sua periodicidade ou sazonalidade.

- Avaliar o impacto que o turismo vem provocando nas produções culturais regionais - - se, como e em que profundidade altera a relação que os produtores culturais mantêm com suas referências culturais tradicionais em função de uma possível nova demanda trazida por esta atividade -, além de alterações provocadas em suas próprias vivências como conseqüência do intercâmbio de informações e da comunicação que invariavelmente se estabelece entre turistas e moradores.

Comun. inf., v.1, n. 1, p. 95-113, jan./jun. 1998 
- Conhecer os grupos produtores de manifestações culturais significativas e identificar os fatores que podem levar à adaptação de suas manifestações ao novo contexto e como estas adaptações podem ser vantajosas do ponto de vista material e da qualidade de suas expressões culturais.

- Avaliar a infra-estrutura existente para que a "capacidade de carga" turística não seja excedida provoque danos ao meioambiente.

- Avaliar o grau de especialização da mão de obra existente e proporcionar seu treinamento, tanto no que diz respeito ao atendimento às necessidades dos turistas quanto, e principalmente, no que diz respeito ao conhecimento e valorização dos recursos naturais e culturais do local.

- Fornecer material informativo aos media e às agências e operadoras de turismo sobre a produção cultural local no sentido de ampliar o conhecimento sobre as manifestações culturais existentes e de estimular a sua valorização, para que a promoção de atividades culturais como elementos de atração turística não signifique, necessariamente, sua mercantilização ou sua "folclorização".

Evidentemente, essas iniciativas poderiam ocorrer a partir do entendimento entre os municípios (ou qualquer outra instância que se ocupe com o fomento ao turismo) e as instituições que, a partir do conhecimento que possuem sobre as manifestações culturais existentes nas diferentes regiões, pudessem indicar as possibilidades de um desenvolvimento turístico que enfatizassem uma integração harmônica entre turistas, populações locais e meio ambiente e privilegiassem uma visão não mercantil do patrimônio histórico, cultural e artístico.

Não seria supérfluo reafirmar aqui que não se está propondo a cristalização, a preservação ou o "resgate" de manifestações culturais "autênticas". O que se pretende é tornar possível e viável, aos produtores culturais, a escolha do que incorporar de outras matrizes culturais, levando em conta o seu próprio contexto cultural, as suas compatibilidades e as suas necessidades, para que qualquer mudança seja fruto de uma opção, sem 


\section{2}

imposições. Sem essa possibilidade de escolha, suas expressões artísticas e culturais tendem a se descaracterizar e a se mercantilizar a ponto de não mais se poder considerá-las como representativas de sua própria cultura. Para que haja esta escolha é necessário conhecer e compreender a cultura, o que pressupõe vivenciá-la e estudá-la.

\section{Abstract}

The author points out the need to change the way of relating tourism and culture. A compensation of this relationship is fundamental for better development of tourism without destroying natural resources or desrespecting to local population. A new outlook to a non-commercial tourism based on the development of historical, cultural, and artistic inheritance.

Key words: tourism, culture, historical and cultural inheritance.

\section{Notas}

1. Sobre cultura de consumo e consumo cultural, uma das abordagens mais completas e atuais sobre o assunto encontram-se em Garcia Canclini, Nestor. "Los estudios sobre comunicación y consumo: el trabajo interdisciplinario en tiempos neoconservadores". Revista Dialogos de la Comunicación, n.32, 1992. Lima, Peru

2. A esse respeito ver matéria "Novo Recife Velho", sobre a "faxina arquitetônica promovida no chamado Recife antigo" e a conseqüente valorização desse espaço urbano. In: Revista VEJA, 20 de janeiro de 1997. A mesma reforma foi realizada na região do Pelourinho, em SalvadorBA.

3. Por efeito multiplicador entende-se o reflexo que o aporte de recursos materiais trazidos pelos turistas realiza ao dinamizar outros setores da economia local, principalmente o comércio de alimentos e certos tipos de produtos e serviços. Para que este efeito multiplicador se concretize é necessária uma política que assegure uma remuneração digna para os trabalhadores. Cf. TRIGO, Luiz G. Godoi. Turismo e qualidade: tendências contemporâneas. Campinas, Papirus, 1993

4. Organización Mundial del Turismo. Previsiones del turismo mundial hasta el año 2000 y despues. OMT. Madrid, septiembre, 1993

5. Revista VEJA, 16 de outubro de 1996

6. O Estado de S. Paulo, 7 de janeiro de 1997

7. Gazeta Mercantil, 7 de março de 1996

Comun. inf., v.1, n. 1, p. 95-113, jan./jun. 1998 
8. O Estado de S. Paulo, 25 de abril de 1996

9. As informações sobre os programas e diretrizes citados foram obtidas pela Internet

10. Revista $V E J A, 16$ de outubro de 1996

11. Jornal $O$ Estado de S. Paulo, 31 de maio de 1994. Naquela ocasião Fortaleza foi escolhida como cenário de uma novela. A matéria esclarece ainda que a cidade ofereceu passagens e estadas em contrapartida, e esperava como retorno o aumento no número de visitantes no verão de 1995.

12. Centro de Estudos Latino-Americanos em Cultura e Comunicação, vinculado à Escola de Comunicações e Artes da Universidade de São Paulo, dirigido pela Profa. Dra. Maria Nazareth Ferreira. Os dados aqui utilizados são parte de pesquisa sobre turismo e cultura no Brasil.

13. Todos os dados usados nas tabelas aqui apresentadas foram retirados de tabelas mais amplas elaboradas pelos pesquisadores do CELACC.

14. Entrevista realizada por pesquisadores do Celacc com a proprictária de uma agência de turismo em Santos- SP.

15. CISNEROS, José E. Identidad cultural e intercambio global. Ejes, circulos y redes culturares desde una cultura propia. In : BARBERO, J.M.. En torno a la identidad latinoamericana. Mexico, UAM, 1992.

\section{Referências bibliográficas}

CISNEROS, José E. Identidad cultural e entercambio global: ejes, circulos y redes culturales desde una cultura propia. In: BARBERO, J. M. (Coord.) En torno a la identidad latinoamericana. Mexico: UAM, 1992.

GARCIA CANCLINI, N. Los estudios sobre comunicación y consumo: el trabajo interdisciplinario en tiempos neoconservadores. Revista Dia-logos de la Comunicación, Lima, Peru, n. 32, 1992.

GARCIA CANCLINI, N. As culturas populares no capitalismo. São Paulo: Brasiliense, 1983.

LAGE, Beatriz H.Gelas, MILONE, Paulo César. Economia do turismo. Campinas : Papirus, 1996.

TRIGO, Luiz G. Godoi. Turismo e qualidade : tendências contemporâneas. Campinas : Papirus, 1993

\section{Outras fontes}

- O Estado de São Paulo - várias edições

- Folha de São Paulo - várias edições

- Gazeta Mercantil - várias edições

- Revista $V E J A$ - várias edições

- Entrevistas realizadas pelos pesquisadores do CELACC

- Internet - Embratur: www.embratur.gov.br/a.htm

Comun. inf., v.1, n. 1, p. 95-113, jan./jun. 1998 